\title{
Hugh Herr
}

By designing a new generation of prosthetic limbs that rely on electronic sensing, Hugh Herr has proven that he can put good ideas into motion. But he aims to go beyond simply restoring lost limb function.

Hugh Herr has a long history of pushing the limits of human physical ability. As a child in rural Pennsylvania, Herr dreamed of becoming the world's best climber. By the age of 15 , he was scaling walls higher than the Eiffel Tower without a rope. But an ill-fated attempt to summit New Hampshire's Mount Washington during a blizzard in 1982 left Herr a double amputee.

Losing his lower legs to frostbite did not stop Herr from climbing. In fact, it motivated him to tackle new challenges. After the accident he began dreaming up ways to improve his prosthetic legs. While still in high school, he crafted a new pair of legs suitable for summiting mountains. "I realized that I didn't have to accept what was given to me," Herr says.

These days, as an associate professor at the Massachusetts Institute of Technology (MIT) in Cambridge, Massachusetts, Herr has little time for climbing. In addition to teaching and attending countless conferences, Herr heads a group at MIT's Media Lab devoted to 'biomechatronics' - the study of how to integrate mechanical elements into the human body. There he and his colleagues investigate the way muscles, tendons and ligaments work and use that information to develop new types of prosthetic devices.

What makes his group's creations special is that the devices do more than simply provide support. Herr uses the latest technology to produce cutting-edge devices that offer amputees an extra lift in their stride. His creations over the past decade include a 'smart' prosthetic knee, which uses electronic sensors to automatically adapt to each individual wearer's gait (Industrial Robot: An International Journal 30, $42-55 ; 2003)$. Herr's team has also produced a motorized plastic brace that helps people with drop-foot—a limp caused by stroke, cerebral palsy or multiple sclerosis-walk normally (IEEE Trans. Neural Syst. Rehabil. Eng. 12, 24-31; 2004).

"Nobody else is going so far in terms of development of the gadgets," says Andy Ruina, a professor of theoretical and applied mechanics at Cornell University in Ithaca, New York.

At a Media Lab symposium in May 2007, Herr unveiled his crowning achievement - the world's first robotic ankle.

When a person with natural legs walks, the muscles connected to the ankle joint provide energy to help propel the limb forward. Unfortunately, most prosthetic legs are equipped with ankles that contain only simple springs, which allow the joint to flex but don't provide much power. As a result, amputees must swing their prosthetic legs forward using energy from their hips - an uncomfortable motion that can cause lower back strain and slow an amputee down.

Herr saw a huge opportunity for improvement in the ankle and began putting his robotic twist on this joint in 2003. But developing a better version was not easy. One of the first prototypes he developed weighed six-and-a-half pounds, roughly three times the weight of a conventional prosthesis. Worse yet, this early prototype only worked when connected to a 13-pound backpack filled with electronics.

Herr's latest prototype, the culmination of four years of work, requires no backpack and weighs less than four pounds. The ankle-a cylinder connected to a small metal box that houses the electronic elements - attaches to a prosthetic foot.

The device uses carbon-composite springs to store energy and a motor powered by a 25 -volt battery to give amputees an extra push when they take a step. Herr, the first person to test the ankle, compares the sensation to that of being on a moving walkway. And thanks to complex circuitry, including a microprocessor and multiple sensors, the prosthetic joint can adjust the foot's position when necessary and add extra power for uphill climbs.

"It's absolutely groundbreaking," says Roy Aaron, director of the Center for Restorative and Regenerative Medicine in Providence, Rhode Island, a program launched by the US Department of Veterans Affairs in 2005 that provides funding for Herr's research. "[The ankle] returns energy in a more physiologic way."

More than 700 US soldiers have lost limbs in Afghanistan and Iraq since October 2001, prompting the US Department of Veterans Affairs to invest heavily in prosthetics research. Herr and his collaborators at the \$7.2 million Center for Restorative and Regenerative Medicine are the beneficiaries of that investment.

So, too, is Garth Stewart, a veteran of the current war in Iraq who lost his lower left leg to a landmine. Stewart tested a prototype of the powered ankle this past summer. "It was surprising to feel something trying to move for me," Stewart says, referring to the mechanical force exerted by the ankle. "But once I got used to its rhythm, it was very pleasant." The robotic ankle could arrive on the market as soon as the summer of 2008 .

Herr, who has a master's degree in mechanical engineering and a $\mathrm{PhD}$ in biophysics, attributes some of his success to the fact that his designs incorporate the subtler principles of human movement. "The way our bodies work is very counter to how engineers think," he explains. He notes,

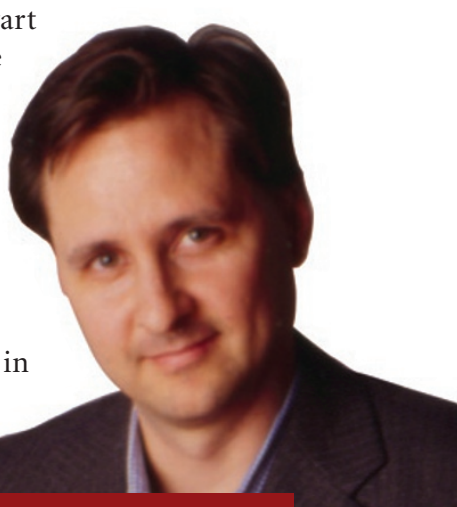

"There is no such thing as a disabled person, there are only disabled technologies. for instance, that the mechanical properties of the human ankle "fundamentally change" as walking speed increases. He says that prosthetic devices should ideally sense body movement and adapt accordingly. And judging from the positive reviews of his prosthetic devices, Herr's approach-he calls it "stealing from nature"-seems to be working.

One of Herr's new pet projects involves designing prostheses for running that will enable amputees to sprint faster than any biological limb could. Herr's design will employ a motor that will cock a spring when the limb is in the air. "[The] foot will hit the ground and then all that energy will be released in this giant burst," he explains, referring to the catapulting motion.

Herr hopes that the prosthetic devices his team is developing will enable athletes participating in the Paralympic Games to run faster and leap farther than Olympians. "There is no such thing as a disabled person, there are only disabled technologies," he says. "The only limitation is the breadth of our creativity."

Cassandra Willyard, New York 